\title{
O ensino de música nas escolas brasileiras, da Colônia à Ditadura civil-militar: faces do consenvadorismo
}

\author{
Music teaching in Brazilian schools, from the Colony to the \\ civil-military dictatorship: faces of conservatism
}

WLADIMIR DE OliVEIRA MARQUES (iD)

MONIQUE ANDRIES NOGUEIRA (D)2

\section{Resumo}

O presente texto tem por objetivo identificar traços do conservadorismo, pedagógico e teórico, que é preponderante na história do ensino de música nas escolas brasileiras. 0 recorte observado tem início com as práticas jesuíticas, ainda no período colonial, passando por 1854, quando foi publicada a primeira norma institucionalizando o ensino de música nas escolas brasileiras, pelo período do Canto Orfeônico - primeira grande política pública de educação musical -, chegando até 1971, quando foi promulgada a Lei de Diretrizes e Bases 5.692, que implementa a disciplina Educação Artística nos currículos escolares. Tendo como referência obras de Fonterrada (2008), Monti (2015), Penna (2013), Jardim $(2009,2012)$ entre outros, são apresentados elementos metodológicos e históricos do ensino de música no Brasil, a fim de se identificar seu caráter conservador, por vezes marcado pelo eurocentrismo e outras por um ufanismo nacionalista, que flerta com o fascismo. Por fim, a reflexão de que, embora tenha sido alvo de diferentes e importantes iniciativas, por vezes bem-intencionadas e conectadas a propostas mais

\footnotetext{
${ }^{1}$ Secretaria Municipal de Educação do Rio de Janeiro, Mestre em Educação, wladimirmarques@yahoo.com

2 Universidade Federal do Rio de Janeiro. Doutora em Educação, e-mail: monique.andries@yahoo.com
}

Rev. Caminhos da Educação: diálogos, culturas e diversidades, Teresina, v. 3, n. 1, p. 108-124, Jan./Abr. 2021 
criadoras, o ensino de música nas escolas brasileiras, no recorte temporal escolhido, seguiu marcado por seu caráter conservador.

Palavras-chave: Canto orfeônico. Educação artística. Educação musical. História da educação musical.

\begin{abstract}
This paper aims to identify traits of conservatism, both pedagogical and theoretical, which is preponderant in the history of music teaching in Brazilian schools. The observed cut begins with the Jesuit practices, still in the colonial period, passing through 1854, when the first norm institutionalizing the teaching of music in Brazilian schools was published, during the period of the Canto Orfeônico - first great public policy of musical education -, arriving until 1971, when the Law of Guidelines and Bases 5,692 was enacted, which implements the discipline Artistic Education in school curricula. With reference to works by Fonterrada (2008), Monti (2015), Penna (2013), Jardim (2009, 2012), among others, methodological and historical elements of music teaching in Brazil are presented, in order to identify its conservative character, sometimes marked by Eurocentrism and others by a nationalist pride, which flirts with fascism. Finally, the reflection that, although it has been the target of different and important initiatives, sometimes well intentioned and connected to more creative proposals, the teaching of music in Brazilian schools, in the chosen time frame, remained marked by its conservative character.
\end{abstract}

Keywords: Orphonic singing. Artistic education. Musical education. History of music education.

\title{
Resumen
}

Este trabajo tiene como objetivo identificar rasgos del conservadurismo, tanto pedagógicos como teóricos, que es preponderante en la historia de la enseñanza de la música en las escuelas brasileñas. El corte observado comienza con las prácticas jesuitas, aún en el período colonial, pasando por 1854, cuando se publicó la primera norma que institucionalizaba la enseñanza de la música en las escuelas brasileñas, durante el período del Canto Orfeônico - primera gran política pública de educación musical -, llegando hasta 1971, cuando se promulga la Ley de Lineamientos y Bases 5.692, que implementa la disciplina Educación Artística en los planes de estudio escolares. Con referencia a trabajos de Fonterrada (2008), Monti (2015), Penna (2013), Jardim (2009, 2012), entre otros, se presentan elementos metodológicos e históricos de la enseñanza musical en Brasil, con el fin de identificar su carácter conservador, a veces marcado por Eurocentrismo y otros por un orgullo nacionalista, que coquetea con el fascismo. Finalmente, la reflexión de que, si bien ha sido blanco de distintas e importantes iniciativas, en ocasiones bien intencionadas

Rev. Caminhos da Educação: diálogos, culturas e diversidades, Teresina, v. 3, n. 1, p. 108-124, Jan./Abr. 2021 
y conectadas a propuestas más creativas, la enseñanza de la música en las escuelas brasileñas, en el marco temporal elegido, quedó marcada por su carácter conservador.

Palabras clave: Canto orfónico. Educación artística. Educación musical. Historia de la educación musical.

\section{Introdução}

O intuito desse texto é apresentar evidências do conservadorismo que marca parte da história da Educação Musical nas escolas Brasileiras, no recorte que vai das práticas jesuíticas, ainda no período colonial, passando por 1854, quando foi publicada a primeira norma institucionalizando o ensino de música nas escolas brasileiras, pelo período do Canto Orfeônico - primeira grande política pública de educação musical -, chegando até 1971, quando foi promulgada a Lei de Diretrizes e Bases 5.692, que implementa a disciplina Educação Artística nos currículos escolares.

Ao longo do texto, procuraremos apresentar elementos metodológicos e históricos do ensino de música no Brasil, em cada um dos momentos selecionados, a fim de se identificar seu caráter conservador, por vezes marcado pelo eurocentrismo e outras por um ufanismo nacionalista, que flerta com o fascismo, e por fim, a quase extinção da educação musical escolar, a partir da Lei de Diretrizes e Bases 5.692/71, com seu viés tecnicista, falsamente moderno, mas igualmente conservador.

\section{Música e cristianismo}

Tendo como principal objetivo a evangelização dos não-cristãos, a Companhia de Jesus foi criada oficialmente em 1540 por Inácio de Loyola. Pouco depois, em 1549, o padre jesuíta Manuel da Nóbrega chegou ao Brasil pela Bahia, acompanhando Tomé de Souza, dando início à história dos jesuítas nas Américas.

Embora a catequese dos povos indígenas fosse a principal razão da chegada da Companhia às terras brasileiras, os religiosos se dedicaram também à educação da população urbana que ali surgia. A organização religiosa inaugurou colégios que ofereciam formação superior, além da instrução básica: leitura e escrita, estabelecendo no Brasil uma importante rede de ensino. Lançando mão da música como uma forma

Rev. Caminhos da Educação: diálogos, culturas e diversidades, Teresina, v. 3, n. 1, p. 108-124, Jan./Abr. 2021 
eficaz de convencimento dos indígenas, o fazer musical dos jesuítas influenciou consideravelmente a formação da cultura brasileira, delineando identidades culturais regionais.

As instituições escolares criadas e mantidas pelos jesuítas no Brasil até o século XVIII incorporaram o fazer musical no currículo com finalidade religiosa, tendo o rigor metodológico de cunho militar e a imposição da cultura lusitana como pilares na construção de suas práticas pedagógicas, desconsiderando a cultura e os valores nativos, dando lugar aos da pátria portuguesa. Toda e qualquer prática e manifestação musical, a partir de então, subordinava-se à Igreja. A rotina básica seguida pelos jesuítas em suas escolas envolvia minuciosa programação das tarefas do dia, estabelecimento de objetivos e metas a serem alcançadas, além do levantamento das atividades realizadas no dia anterior. Esta rotina seguia um conjunto de normas denominado "Exercícios espirituais" - abrangendo todas as esferas da atividade humana: regras para o "bom" desenvolvimento da imaginação, para dar esmolas, para "sentir" de maneira adequada, enfim, nas palavras de Fonterrada, trata-se do "controle absoluto do psiquismo humano" (2008, p. 209). A tônica da aprendizagem era a prática exaustiva, mediante exercícios que progrediam do simples para o complexo, permitindo que a execução de determinada atividade fosse gradualmente aperfeiçoada. Dentro desses princípios filosóficos e metodológicos surge no Brasil a primeira proposta pedagógica em educação musical, fazendo com que curumins crianças indígenas - fossem treinados a tocar música europeia. Com a finalidade de estimular o debate sobre a pluralidade de pontos de vista acerca da educação jesuítica, trago as palavras de Amato:

As primeiras informações musicais eruditas foram trazidas ao Brasil pelos portugueses, por intermédio dos jesuítas. Esses missionários, dispostos a conquistar novos servos para Deus, encontraram na arte um meio de sensibilizar os indígenas. A música que os jesuítas trouxeram era simples e singela, as linhas puras do cantochão, cujos acentos comoveram os indígenas, que, desde a primeira missa, deixaram-se enlear por tais melodias. (AMATO, 2006, p.146)

O período colonial não trouxe mudanças. Assim como a educação geral, a educação musical se mantinha vinculada à Igreja, o que significava a continuação dos hábitos culturais eurocêntricos, além da permanência da prática baseada na repetição. Rev. Caminhos da Educação: diálogos, culturas e diversidades, Teresina, v. 3, n. 1, p. 108-124, Jan./Abr. 2021 
Mais tarde, com a chegada da corte portuguesa ao Brasil, fugindo de Napoleão Bonaparte e seu exército, no início do século XIX, modelos musicais europeus foram implementados e replicados, subjugando práticas musicais da cultura local. Entretanto, mudanças surgiram: a música não mais se limitava às Igrejas. Em 1813, D. João VI inaugura o "Real Teatro de São João" - atual Teatro João Caetano, no Centro do Rio de Janeiro -, um espaço que passa a receber companhias estrangeiras de óperas, operetas e outros gêneros. Apesar da secularização da prática musical, a metodologia formalmente usada para o ensino de música permanecia a mesma, ou seja, ainda era comum o ensino de música baseado em métodos progressivos, na memorização e no confronto entre propostas e metas alcançadas, sendo o repertório praticado predominantemente europeu. Paralelamente, uma revolução acontecia à margem das instituições: era consolidada no país a prática informal da música popular, rompendo com padrões disciplinares de cunho pragmático e religioso, tendo como principais características a espontaneidade e a criatividade, prezando pela habilidade instrumental e a improvisação.

\section{As primeiras normas legais}

A primeira documentação oficial do ensino de música no currículo escolar, aparece no primeiro Regulamento do Colégio Pedro II, em 1838, que incluía Música Vocal como disciplina ao longo dos oito anos do curso. A instituição, fundada no Rio de Janeiro em 1837, assumiu o caráter de modelo paras as congêneres no país (JARDIM, 2012). Interessante notar que o pioneirismo do Colégio Pedro II, marcado pela valorização do ensino de música, se manteve mesmo no período pós 1971, quando a legislação praticamente "sepultou” este ensino ao criar a atividade polivalente Educação Artística. Em função de diferentes motivos que não cabem serem discutidos no espaço desse texto, o fato é que no período da Educação Artística houve uma preponderância da linguagem visual, o que praticamente relegou o ensino de Música e o de Teatro a espaços não escolares. Contudo, o Colégio Pedro II manteve a disciplina Educação Musical, ao lado da Educação Artística, que abordava exclusivamente conteúdos plásticos e visuais.

Rev. Caminhos da Educação: diálogos, culturas e diversidades, Teresina, v. 3, n. 1, p. 108-124, Jan./Abr. 2021 
Também de notável nesse período a fundação do Conservatório de Música do Rio de Janeiro, em $1848^{3}$, pelas mãos de Francisco Manuel da Silva - o compositor do Hino Nacional Brasileiro e músico de grande destaque no Rio de Janeiro -, que, apesar da total ausência de investimentos de recursos públicos, demarca o início da presença da música no espaço escolar institucional (JARDIM, 2012).

O primeiro documento que teve por objetivo a institucionalização do ensino de música nas escolas brasileiras, apresentando os primeiros parâmetros legais para a sua realização, foi o Decreto no 1.331 , de 1854, elaborado durante o Regime Imperial. Segundo o decreto, o ensino de música deveria se estabelecer em dois eixos: "noções de música" e "exercícios de canto", não especificando nada além disso. Posteriormente, em 1890, foi promulgado o Decreto no 981 , legislando sobre a música nas escolas no início do período republicano. A presente norma estabelecia a exigência de formação especializada aos professores de música, além de estipular a realização de concurso público para o ingresso na carreira. Era o surgimento da profissão. Legalmente, é o surgimento do ensino de música nas escolas brasileiras.

\section{A Escola Nova e Mário de Andrade}

No século XX, os ecos da Escola Nova de John Dewey são reverberados no Brasil através das ideias de Anísio Teixeira. De acordo com a filosofia escolanovista, as artes, principalmente a música, deixam de ser abordadas como monopólio daqueles mais talentosos e passam a ser vistas como elemento fundamental na formação integral, devendo ser acessível a todos. Na proposta da Escola Nova, o ensino de artes não se restringia aos talentosos, aos aptos, e sim a todos, contribuindo para a formação integral do aluno. Surge aí um espaço para o professor especialista. Todavia, enquanto o pensamento escolanovista reivindicava a democratização do ensino de música, a educação musical, por sua vez, seguia na já citada dinâmica extremamente tradicional de ensino, voltada para a prática de exercícios técnicos progressivos, para o trabalho

\footnotetext{
${ }^{3}$ Também conhecido como Imperial Conservatório de Música, foi criado a partir de decreto de 1841, porém só iniciou suas atividades em 1848. Influenciou a criação de conservatórios em São Paulo, Pará e Bahia, dando origem à primeira instituição de ensino superior de música, a Escola Nacional de Música da Universidade do Brasil, atual Escola de Música da UFRJ.
}

Rev. Caminhos da Educação: diálogos, culturas e diversidades, Teresina, v. 3, n. 1, p. 108-124, Jan./Abr. 2021 
enraizado na repetição e na memorização e para a aquisição do repertório erudito europeu.

Ao passo que a proposta de Anísio Teixeira reivindicava a universalização do ensino de artes, o Conservatório Brasileiro de Música prezava pelo campo especializado. Em consonância com os recentes conservatórios europeus e americanos, com professores de formação europeia, os cursos dos conservatórios privilegiavam o ensino de instrumento, tal qual o costume da época, uma vez que prevalecia a associação ensino de música/ensino de instrumento, intrinsicamente.

Ainda sobre o ensino especializado de música, na primeira década do século XX foi inaugurado em São Paulo o Conservatório Dramático e Musical. Inspirado no Conservatório de Paris, estabeleceu padrões artístico-pedagógicos, servindo de referência para as demais escolas especializadas no ensino de música, não só em São Paulo, mas em todo o território nacional, sendo um marco no ensino de música no Brasil. E é a partir das ideias nacionalistas de um de seus professores, Mário de Andrade, que paradigmas serão rompidos.

A trajetória de Mário de Andrade na instituição paulista tem início em 1911, quando aos 18 anos ingressou no Curso de Piano. Em 1913, prodigiosamente, já era professor substituto do Curso de História da Música, já tendo lecionado teoria musical e solfejo como "aluno praticante" no ano anterior (BARONGENO, 2010). Em 1922, ano em que ocorreu a Semana de Arte Moderna, Mário de Andrade foi nomeado catedrático de Dicção, História do Teatro, Estética e História da Música do conservatório, posição essa exercida até 1945, quando ocorreu sua morte.

Como professor, na onda do movimento modernista, Mário de Andrade sempre prezou por um ensino de música calcado em métodos sociológicos, visando a um entendimento mais íntimo e legítimo da arte, considerada por ele um fenômeno de grande complexidade. Entusiasta do folclore e da música popular, Andrade defendia que a finalidade do conservatório paulista não deveria ser a formação de músicos virtuosos, mas sim a democratização e universalização da música Brasil adentro. Assim, na década de 1920 a brasilidade começa a ganhar espaço entre os educadores musicais, substituindo as tradições eurocêntricas, em voga até então. Mas

Rev. Caminhos da Educação: diálogos, culturas e diversidades, Teresina, v. 3, n. 1, p. 108-124, Jan./Abr. 2021 
outro grande músico brasileiro, também com ideias e propósitos inovadores, vislumbrou a universalização do ensino de música em nossas escolas.

\section{O Canto Orfeônico e Villa-Lobos}

Nesse ponto da história, surge a figura de Heitor Villa-Lobos e sua ideia de implantação do Canto Orfeônico nas escolas públicas brasileiras, a partir da década de 1930. Um marco na história da educação musical no Brasil do século XX. Nas palavras de Requião:

[...] é consenso entre os educadores musicais e pesquisadores que a prática do canto orfeônico nas escolas, como parte de uma política pública, é um marco na implementação de políticas públicas para o ensino de música nas escolas brasileiras (REQUIÃO, 2013, p.172).

É perceptível um alinhamento entre os ideais escolanovistas e o pensamento de Villa-Lobos. Já na primeira década do século XX havia muitas críticas em relação ao ensino de música nas escolas públicas, considerado defasado em comparação às práticas ocorridas nas salas de aula europeias com seus ares de civismo estimulado pelas práticas orfeônicas. Sob tal perspectiva, o ensino de música nas escolas brasileiras gerava muita insatisfação pelas práticas pedagógicas e métodos usados: ora a abordagem envolvia certo nível de complexidade, pertinente apenas aos estudantes que visavam à especialização na área - como nos conservatórios -, ora a música era encarada como uma atividade recreativa, sem objetivos educacionais definidos. $\mathrm{O}$ ensino de música era baseado em extremos muitas vezes permeados pela aleatoriedade. A proposta de Villa-Lobos diferenciava-se do ensino musical profissional, presente nos conservatórios: ao passo que tais instituições prezavam pelo aprimoramento técnico visando à performance, o canto orfeônico tinha como intuito a democratização da prática e dos fundamentos teóricos musicais. É a pedagogia musical em diferentes abordagens.

Além da ampla difusão do ensino de música, os escolanovistas e Villa-Lobos convergiam em relação ao caráter nacionalista da proposta orfeônica. Para os entusiastas,

as práticas despertariam os alunos não só para o civismo, mas também para a disciplina e o interesse pelas artes (MONTI, 2015).

Rev. Caminhos da Educação: diálogos, culturas e diversidades, Teresina, v. 3, n. 1, p. 108-124, Jan./Abr. 2021 
Implementado através da promulgação do Decreto no 19.890 de 1931, assinado pelo então presidente Getúlio Vargas, o canto orfeônico se tornou disciplina obrigatória nos currículos escolares no Rio de Janeiro, antigo Distrito Federal, alcançando todo o ciclo educacional e atendendo a escolas pré-primárias, primárias, secundárias, além das técnico-profissionais. Posteriormente, através do Decreto $\mathrm{n}^{\circ}$ 24.794, de 1934, tornou-se disciplina obrigatória em todos os estabelecimentos de educação primária e secundária no país. Sua aplicação nas escolas seguia parâmetros estabelecidos pela Portaria Ministerial no 300, de 7 de maio de 1946. Lisboa (2005) enumera tais parâmetros:

a) estimular o hábito do perfeito convívio coletivo, aperfeiçoando o senso de apuração do bom gosto.

b) desenvolver os fatores essenciais da sensibilidade musical, baseados no ritmo, no som e na palavra.

c) proporcionar a educação do caráter em relação à vida social por intermédio da música viva.

d) incutir o sentimento cívico, de disciplina, o senso de solidariedade e de responsabilidade no ambiente escolar.

e) musicalizar todos os escolares.

f) despertar o amor pela música e o interesse pelas realizações artísticas

g) promover a confraternização entre os escolares.

h) manter a interpretação justa dos hinos oficiais entre os escolares [finalidade acrescentada para os objetivos do curso normal]. (LISBOA, 2005, p. 49)

Sob um programa de ensino cuja ordem de dificuldade se desenvolvia de forma crescente através das séries das escolas primárias, secundárias e técnicoprofissionais, ao fim dos ciclos o aluno deveria estar familiarizado com aspectos importantes da leitura e escrita musical como: "elementos gráficos" (pauta, figuras rítmicas, notas, claves, entre outros), "elementos rítmicos" (leitura rítmica, ditados rítmicos, compassos simples e compostos, quiálteras, síncope, andamento, entre outros), “elementos melódicos"(ditados melódicos, escalas maiores e menores, solfejos, entre outros), “elementos harmônicos”(intervalos, tríades e tétrades, arpejos, tonalidades, série harmônica, entre outros), "prática orfeônica" (exercícios de respiração, afinação orfeônica, exercícios de vocalização, manossolfa falado e entoado, entre outros), "história e apreciação musical" (lendas brasileiras, audição de discos, noções de história da música, entre outros). O canto orfeônico no Brasil não tinha o intuito de formar cantores virtuosos, mas sim incentivar a experiência musical,

Rev. Caminhos da Educação: diálogos, culturas e diversidades, Teresina, v. 3, n. 1, p. 108-124, Jan./Abr. 2021 
divulgando o repertório popular, descoberto por meio de intensas pesquisas de campo.

Em excursões pela Europa, Villa-Lobos conheceu métodos ativos de educação musical e se identificou significativamente com a proposta do educador musical húngaro Zoltán Kodály, especialmente a fundamentação da proposta, baseada no uso de material folclórico e popular, no ensino de música através do canto coral democratizando o acesso ao fazer musical - e no uso do manossolfa. Entretanto, Monti (2015) destaca que não fora Kodály a influenciar Villa-Lobos, mas sim o contato com o músico Leo Kestenberg, quando o brasileiro passou por Praga na segunda metade do século XX - assim como Kodály também fora influenciado por Leo. Como argumento, Monti (2015) apresenta o conflito cronológico entre as propostas: ao passo que Villa-Lobos implementou sua proposta na década de 1930, o húngaro iniciou o trabalho nas escolas na década de 1950 (MONTI, 2015).

Villa-Lobos acreditava que os jovens do Brasil precisavam de uma pedagogia musical baseada em exercícios contínuos de pulsação, sendo marchas e cantos marciais ideais para a proposta, uma vez que, ainda de acordo com o músico, o brasileiro assimilava aspectos rítmicos informal e intuitivamente com muita facilidade e sensibilidade. Nesse contexto, o método orfeônico difundido por Villa-Lobos foi paulatinamente sendo assimilado pela política nacionalista do governo Vargas, chegando, segundo Fonterrada (2008, p. 214), a enaltecer "a figura do ditador e a pátria" em suas ações musicais. Ainda de acordo com a autora, Getúlio Vargas percebeu a linguagem musical - aspectos rítmicos, ligados à marcação do tempo, especificamente - como relevante ferramenta de arregimentação e padronização das massas. Dessa forma, Villa-Lobos incorpora as noções de disciplina e civismo em seus objetivos, que resultavam em grandiosas apresentações públicas - e demonstrações de força e organização - que envolviam corais formados por algumas dezenas de milhares de vozes em estádios de futebol. Nas palavras de Monti:

A marcha poderia ser vista pelo governo de Getúlio como um instrumento subjetivo para a construção de um modelo de sociedade, como uma nação que anda sincronizada, em fila, passo a passo na manutenção harmoniosa do conjunto. (MONTI, 2015, p. 87)

Rev. Caminhos da Educação: diálogos, culturas e diversidades, Teresina, v. 3, n. 1, p. 108-124, Jan./Abr. 2021 
Uma das maiores dificuldades encontradas na proposta orfeônica foi a formação de professores. Na década de 1930, foram criados no Distrito Federal os “Cursos de Orientação e Aperfeiçoamento do Ensino de Música e Canto Orfeônico”, seguindo o fio da "Reforma Capanema"4, que consistiam em cursos de curta duração, ministrados pelo próprio Villa-Lobos, contando com a participação de músicos convidados, entre eles Lorenzo Fernandez. O objetivo do curso era apresentar aos docentes do magistério público conceitos de teoria musical e de técnicas referentes à prática orfeônica, visando à aplicação nas escolas públicas. Mais tarde, na década de 1940, o governo Vargas institui por meio do Decreto no 4.993 de 1942 o "Conservatório Nacional de Canto Orfeônico", tornando obrigatória a participação dos docentes nos cursos, já implementados nas cidades do Rio de Janeiro e de São Paulo. Em 1946, já na gestão de Eurico Gaspar Dutra, foram regulamentados os parâmetros do ensino de canto orfeônico - organização, finalidade, entre outros por meio do Decreto n ${ }^{\circ}$ 9.494, conhecido como "Lei Orgânica do Ensino de Canto Orfeônico". Todavia, as dimensões quase que continentais do país, além da má qualidade das estradas, impedindo o deslocamento, tornou o cumprimento de tal exigência algo inalcançável (FONTERRADA, 2008).

Em meio ao polêmico envolvimento do projeto orfeônico com as políticas varguistas do Estado Novo, Villa-Lobos sofreu diversas críticas. Por outro lado, a atuação do maestro é de extrema relevância no cenário educacional brasileiro, uma vez que nos deixou como legado a primeira - e única - política pública de ensino de música no país.

\section{Sai o Canto Orfeônico, entra a Educação Musical}

A presença da música vocal na rede pública de ensino, instituída pela política orfeônica, possibilitou a expansão da música entre a população brasileira por gerações, democratizando e valorizando aspectos da cultura do Brasil. Entretanto, a Lei de Diretrizes e Bases (LDB) 4.024 de 1961, elimina o termo Canto Orfeônico, dando

\footnotetext{
${ }^{4}$ Reforma do sistema educacional brasileiro realizada durante o Estado Novo (1930-1945) e capitaneada pelo então ministro da educação e saúde Gustavo Capanema. Tal reforma consistiu em uma série de decretos denominados Leis Orgânicas do Ensino, caracterizados pela articulação junto aos ideários nacionalistas de Vargas e seu projeto político.

Rev. Caminhos da Educação: diálogos, culturas e diversidades, Teresina, v. 3, n. 1, p. 108-124, Jan./Abr. 2021
} 
lugar à expressão Educação Musical. Esta mudança se deu por meio do Parecer $\mathrm{n}^{\circ}$ 383/62 homologado pela Portaria Ministerial n 288/62 e, provavelmente, ocorreu na intenção de demarcar uma espécie de rompimento com as políticas presentes no período varguista, já que há controvérsias em relação à sua gestão. Apesar da mudança na nomenclatura, não houve mudanças significativas na abordagem do ensino de música nas escolas em relação à prática orfeônica, principalmente porque a grande maioria dos professores de música haviam sido formados pelo modelo anterior.

Paralelamente ao que ocorria nas escolas públicas, havia um movimento crescente de aproximação entre músicos brasileiros e a educação musical. Artistas como Anita Guarnieri, Sá Pereira, Gazzi de Sá e Lorenzo Fernandes, dentre outros, eram conhecedores e entusiastas do trabalho de autores que revolucionaram a educação musical europeia desde as primeiras décadas do século XX, como Jacques Dalcroze e Carl Orff. Essas novas tendências tinham como base a desvinculação da aula de música do ensino de instrumento, incentivando a prática musical, o uso do corpo e a ênfase no aprimoramento da percepção auditiva através de jogos e brincadeiras, do uso de instrumentos de percussão e do convite à criação e improvisação, estimulando a espontaneidade, em oposição à proposta villalobiana. Contudo, apesar de alinhados com as correntes metodológicas e procedimentais mundo afora, os músicos em questão atuavam em escolas especializadas dentro do contexto conservatorial -, não trazendo mudanças significativas à rede pública de ensino.

Embora em ampla sintonia com o que ocorria na educação musical mundial, os educadores brasileiros citados trabalhavam em escolas especializadas de música, atingindo o ensino público apenas indiretamente. Este muito pouco mudara em relação à música, mesmo após a substituição do Canto Orfeônico pela Educação Musical em 1964. (FONTERRADA, 2008, p. 214)

Ainda sob tal perspectiva, é de grande valia trazer ao presente trabalho o nome do professor alemão Hans-Joachim Koellreuter, contemporâneo à política orfeônica - chegou ao Brasil em 1937, sendo o principal expoente do movimento "Música Viva". Sob o lema "combate pela música que revela o eternamente novo, isto é: por

Rev. Caminhos da Educação: diálogos, culturas e diversidades, Teresina, v. 3, n. 1, p. 108-124, Jan./Abr. 2021 
uma arte musical que seja a expressão real da época e da sociedade" (MATEIRO, 2006, p.115-116), o movimento teve o apoio de músicos como Cláudio Santoro, Edino Krieger e César Guerra Peixe, e prezava por uma educação musical baseada na criação, na função social do criador, na coletividade e na contemporaneidade como elemento renovador.

\section{A implementação da Educação Artística}

Após a implementação da Lei $n^{\circ} 4.024 / 61$, por volta da segunda metade da década de 1960, decorrente de um modelo socioeconômico desenvolvimentista em implantação no país, podemos observar o surgimento de uma tendência tecnicista na educação brasileira. A partir de então, o golpe civil-militar favorece a implementação de um mercado de consumo e industrialização de hegemonia estado-unidense. Sob tal perspectiva, a educação brasileira passa por uma reforma que a ajusta ao âmbito da sociedade industrial, que percebe como função primária da escola preparar para o trabalho e para o consumo. Assim, tomemos as palavras de Laval (2004) que mesmo aplicadas à cena europeia são certeiras quando empregadas à conjuntura brasileira: "a industrialização e a mercantilização da existência redefinem o homem, como um ser essencialmente econômico" (LAVAL, 2004, p. 43).

No presente contexto e sob tais ideais, a chegada da LDB no 5.692/1971 traz uma gigantesca reviravolta no ensino de música nas escolas: por meio do artigo $7^{\circ}$, regulamenta a "Educação Artística" no currículo escolar no ensino de $1^{\circ}$ e $2^{\circ}$ grau, ancorada na prática polivalente do ensino das artes, ou seja, um único professor responsável por ministrar aulas abrangendo as diversas linguagens artísticas (música, artes plásticas, teatro e desenho), interrompendo assim a consolidação do ensino de música nas escolas. A experiência impossibilitou o estabelecimento de qualquer proposta consistente para a presença das artes na escola, resultando em diversos problemas. A formação do professor polivalente mostrou-se extremamente ineficaz, gerando docentes com muitas deficiências na abordagem das linguagens, cujas complexidades e especificidades não eram contempladas por não haver tempo hábil para maior aprofundamento nos assuntos trabalhados. Essa proposta resultou na superficialização de conteúdos artísticos na escola.

Rev. Caminhos da Educação: diálogos, culturas e diversidades, Teresina, v. 3, n. 1, p. 108-124, Jan./Abr. 2021 
A defesa da educação artística se dava por meio do conceito modernista: pesquisa e experimentação. Esta proposta está essencialmente ligada à liberação das emoções e à valorização do folclore e da música popular, além da interação com outras linguagens. Embora a proposta se alinhe às correntes experimentais de educação musical ao se apoiar nos princípios da criação e improvisação, tal aproximação se deu apenas superficialmente, pois a proposta caracterizava-se pela total falta de autonomia do professor. Foi o momento de grande expansão da indústria do livro didático, na qual a Educação Artística não ficou de fora: livros didáticos que se limitavam a atividades desconectadas do contexto social, baseadas em um fazer artístico mecânico, pobre e reprodutivista, com ênfase em motivos cívico-militares, deslegitimando o lugar da arte na escola, uma vez que ela ocupava um lugar menor, descontextualizada, à margem. A presente ideia era comum às escolas durante as décadas de 1970 e 1980, época da ditadura civil-militar.

Antes de fechar a análise sobre o ciclo da Educação Artística, optamos por trazer um relevante debate não contemplado ao longo do presente artigo, que diz respeito à análise de Penna (2013) sobre a relação entre o fim da política orfeônica e o início da educação artística. Segundo a autora, a polivalência no ensino de artes instituída pela norma de 1971 apenas oficializou uma tendência já dominante na prática escolar. Com o esvaziamento do projeto do canto orfeônico motivado pelo fim das condições políticas que lhe davam suporte, boa parte dos educadores recorreu à nova corrente, tendo como um dos motivos a sua frágil formação musical.

Ainda sobre o contexto de implementação da educação artística e a formação musical dos docentes, Jardim (2009) argumenta que, embora a Lei n 5.692/71 seja responsabilizada pelo desmonte de todo o conhecimento musical no âmbito escolar, não é possível saber em que termos essa educação musical era realizada, qual o perfil profissional exigido dos profissionais, a trajetória de formação dos docentes - além das especializações - e quais conteúdos eram trabalhados. De acordo com a autora, não temos subsídios que nos permitam conhecer aspectos qualitativos ou ainda concluir como e quão boa era a educação musical escolar antes da referida lei, uma vez que a educação musical ainda é uma área de estudos recentes no país, sendo a pesquisa histórica que a cerca ainda incipiente, fazendo com que muitos pesquisadores

Rev. Caminhos da Educação: diálogos, culturas e diversidades, Teresina, v. 3, n. 1, p. 108-124, Jan./Abr. 2021 
partam de presunções, podendo assumir encaminhamentos e resultados inconsistentes.

Quanto à gestão, o canto orfeônico se estruturava em estratégias políticas, administrativas e forte fundamentação filosófica (MONTI, 2015). Politicamente, Villa-Lobos dialogava muito confortavelmente com o governo Vargas, o que nos leva a crer que a grandiosidade e o crescimento do projeto orfeônico se deram, em parte, por essa relação com o Estado. Afinal, sem interesse e financiamento estatal, fatalmente o projeto estaria limitado em alcance e notoriedade, justificando também o alto teor nacionalista do programa, em alinhamento às ideias varguistas. Entretanto, de acordo com as observações de Penna (2013), os esforços de Villa-Lobos ao longo da gestão do programa não foram efetivos no intuito de formar docentes musicalmente.

Penna (2013) também nos lembra que a Lei 5.692/71 é pioneira ao estabelecer em seu Artigo 44 o dever do Estado em oferecer ensino público e gratuito a crianças e adolescentes entre os sete e quatorze anos de idade por todo o $1^{\circ}$ grau - atual ensino fundamental, de acordo com a Lei de Diretrizes e Bases 9.394/96 - proporcionando mudanças significativas, uma vez que em uma escola com maior alcance social, algumas práticas pedagógicas eficazes em uma escola com menor amplitude já não seriam adequadas. Comparativamente, a taxa de escolarização entre a população de cinco a dezenove anos beirava os 22\% em 1940, época da proposta de Villa-Lobos. Por fim, a autora conclui que apesar dos diversos problemas que norteiam a prática da educação artística e seus possíveis efeitos sobre a educação musical nas escolas, sua implementação em meio à expansão da oferta de educação pública e gratuita amplia o alcance do ensino de artes, historicamente restrito a privilegiados, colocando-o como parte integrante da formação escolar das massas.

\section{Considerações finais}

Ao longo deste artigo, procuramos demonstrar, no recorte escolhido, as diversas fases do ensino de música nas escolas brasileiras, assinalando suas diferenças. No entanto, como conclusão, percebemos que a par de suas diferenças, o traço de conservadorismo é constante. Primeiramente, no período colonial, o traço Rev. Caminhos da Educação: diálogos, culturas e diversidades, Teresina, v. 3, n. 1, p. 108-124, Jan./Abr. 2021 
eurocentrista e messiânico; mais tarde, a base eurocentrista segue marcando a produção conservatorial.

Já no período republicano, nas décadas iniciais do século $\mathrm{XX}$, quando movimentos nacionalistas ganham força, o caráter ufanista do modelo do canto orfeônico flerta com o fascismo, mantendo assim seu caráter conservador. $\mathrm{E}$ as breves iniciativas da década de 1960, ainda que com caráter aparentemente mais liberal e criador, não ultrapassaram os limites do âmbito alternativo, o que não as torna historicamente relevantes em termos de educação pública escolar. Por fim, a Educação Artística, como manifestação típica do tecnicismo pedagógico, materialização do ideal educacional da ditadura militar, obviamente conservador e retrógrado, que praticamente retira a educação musical do sistema escolar.

Embora compreendamos e prestemos homenagem ao compromisso dos educadores musicais brasileiros que, ao longo do período assinalado, trabalharam pela efetivação do ensino de música de forma democrática, é fato que a marca do conservadorismo se manteve. Nesse sentido, esperamos que a reflexão aqui apresentada ofereça elementos aos atuais educadores para promoverem uma mudança real, dando à educação musical um caráter emancipatório, com vistas a uma transformação da sociedade.

\section{Referências}

AMATO, Rita de Cássia Fucci. Breve retrospectiva histórica e desafios do ensino de música na educação básica brasileira. Revista Opus, v. 12, p.144-166, 2006.

BARONGEO, Luciana. Mário de Andrade, professor do Conservatório Dramático e Musical de São Paulo In: I SIMPÓSIO BRASILEIRO DE PÓS-GRADUANDOS EM MÚSICA, XV COLÓQUIO DO PROGRAMA DE PÓS-GRADUAÇÃO EM MÚSICA DA UNIRIO, 2010, Rio de Janeiro. Anais do I Simpom. Rio de janeiro, 2010. P.608-616.

BRASIL. Approva o Regulamento para a reforma do ensino primario e secundario do Municipio da Côrte. Decreto n ${ }^{\circ} 1.331-A$, de 17 de fevereiro de 1854. Coleção de Leis do Império do Brasil - 1854.

- Approva o Regulamento da Instrucção Primaria e Secundaria do Districto Federal. Decreto no 981, de 8 de novembro de 1890. Coleção de Leis do Brasil - 1890.

Rev. Caminhos da Educação: diálogos, culturas e diversidades, Teresina, v. 3, n. 1, p. 108-124, Jan./Abr. 2021 
Dispõe sobre a organização do ensino secundário. Decreto $n^{\circ} 19.890$, de 18 de abril de 1931. Diário Official - 1/5/1931.

Cria, no Ministério da Educação e Saúde Pública, sem aumento de despesa, a Inspetoria Geral do Ensino Emendativo, dispõe sôbre o Ensino do Canto Orfeônico, e dá outras providências. Decreto no 24.794, de 14 de Julho de 1934. Diário Oficial da União Seção $1-26 / 7 / 1934$.

Ministério de Educação e Saúde. Institui o Conservatório Nacional de Canto Orfeônico, e dá outras providências. Decreto-lei no 4.993, de 26 de novembro de 1942. Diário Oficial da União - Seção 1 - 28/11/1942.

Ministério de Educação e Saúde. Lei Nacional do Canto Orfeônico. Decreto-lei n ${ }^{\circ}$ 9.494, de 22 de julho de 1946. Diário Oficial da União - Seção 1 - 27/7/1946.

. Ministério da Educação e Cultura. Lei de Diretrizes e Bases da Educação Nacional. Lei no 4.024, de 20 de dezembro de 1961. Coleção de Leis do Brasil - 1961, p.51, vol. 7.

. Ministério da Educação e Cultura. Lei de Diretrizes e Bases da Educação Nacional. Lei n ${ }^{\circ}$ 5.692, de 11 de agosto de 1971. Coleção de Leis do Brasil - 1971, p.59, vol. 5.

Ministério da Educação e do Desporto. Lei de Diretrizes e Bases da Educação Nacional. Lei no 9.394, de 20 de dezembro de 1996. Diário Oficial da União - Seção 1 23/12/1996.

FONTERRADA, Maria Trench de Oliveira. De tramas e fios: um ensaio sobre música e educaşão. $2^{\text {a }}$. edição. São Paulo: Editora UNESP; Rio de Janeiro: Funarte, 2008.

JARDIM, Vera Lúcia Gomes. Institucionalização da profissão docente - o professor de música e a educação pública. Revista da ABEM, Porto Alegre, V. 21, p.15-24, 2009/Mar.

A Música no Currículo Oficial: um estudo histórico pela perspectiva do livro didático. Revista Música Hodie, Goiânia, V.12, n.1, p. 167-174, 2012.

LAVAL, Christian. A nova linguagem da escola. In: LAVAL, Christian. A escola não é uma empresa: o neoliberalismo em ataque ao ensino público. $1^{\text {a }}$ edição. Londrina: Ed. Planta, 2004. P.4364.

LISBOA, Alessandra Coutinho. Villa-Lobos e o canto orfeônico: música, nacionalismo e ideal civilizador. 2005. 183fls. Dissertação (Mestrado em Música). Instituto de Artes, Universidade Estadual Paulista, UNESP, São Paulo, 2005.

MATEIRO, Teresa da Assunção Novo. Educação musical nas escolas brasileiras: retrospectiva histórica e tendências pedagógicas atuais. Revista Nupeart, v.4, n.4, p.115 - 135, set. 2006.

MONTI, Ednardo Monteiro Gonzaga do. Polifonias Politicas, Identitárias e Pedagógicas: VillaLobos no Instituto de Educação do Rio de Janeiro na Era Vargas. 2015. 262p. Tese (Doutorado em Educação) - Faculdade de Educação da Universidade do Estado do Rio de Janeiro, UERJ, Rio de Janeiro, 2015.

Rev. Caminhos da Educação: diálogos, culturas e diversidades, Teresina, v. 3, n. 1, p. 108-124, Jan./Abr. 2021 
PENNA, Maura. A Lei 11.769/2008 e a música na educação básica: quadro histórico, perspectivas e desafios. Intermeio, Campo Grande, v. 19, p.53-75, 2013.

REQUIÃO, Luciana. Música nas escolas: mercadoria ou formação humana? Revista Educação: Teoria e Prática. Rio Claro. Vol. 23, n.4, p.169-181, 2013/Mai-ago.

RECEBIDO: 01/02/2021

APROVADO:03/04/ 2021

RECEIVED: 01/02/2021

APPROVED: 03/04/ 2021

RECIBIDO: 03/02/ 2021

APROBADO: 03/04/ 201

Rev. Caminhos da Educação: diálogos, culturas e diversidades, Teresina, v. 3, n. 1, p. 108-124, Jan./Abr. 2021 
Rev. Caminhos da Educação: diálogos, culturas e diversidades, Teresina, v. 3, n. 1, p. 102-118, Jan./Abr. 2021 